\title{
WORK WITH PERSONAL BIOGRAPHY OF STUDENTS OF SPECIALTY "GERIATRIC CARE" AT MEDICAL COLLEGE OF TRAKIA UNIVERSITY, STARA ZAGORA
}

\author{
M. Dimova*, H. Milcheva \\ Medical College, Trakia University, Stara Zagora, Bulgaria
}

\begin{abstract}
Introduction. Each life story, every biography is unique and distinctive, because each person is unique. In geriatric care the study of the history of adult life helps geriatric specialists to better understand and build quality care plan according to their individual characteristics and needs, which requires biographical centered approach.

The purpose of this study is to explore the attitudes and opinions of students of specialty "Geriatric care" at Medical College of Trakia University, Stara Zagora, to work with their personal biography in the training process.

Materials and methods: direct group survey, statistical processing and data analysis. A survey of 15 students of specialty "Geriatric Care" is made about their opinion on the work with their personal biography in the learning process.

Discussion and results: The most important competencies of geriatric specialists are based on proper communication with older people in the process of caring for them, assuming that each depending on care person has to live according to their individual values, needs, cultural and religious affiliation.

Before start working with the elderly and before applying the "Work with biography" method the geriatric specialists should acquire theoretical knowledge and to form practical skills by self-analysis, upon presentation of their personal biography working in pairs and in groups. The analysis of the conducted survey shows that at the beginning of the course students are afraid of revealing very personal and traumatic experiences and need more practical exercises and time for introspection and training to work with biographical sheet.
\end{abstract}

Key words: training, method for work with biography, work with personal biography, biographical centered geriatric care

\section{INTRODUCTION}

Each life story, each biography is unique and distinctive, as each individual is unique.

At the heart of geriatric care is the elderly person, with his/her individuality, which requires the use of a biographical approach.

Geriatric care requires studying the life history of an older person, which helps geriatric specialists to better understand him/her and to develop a good plan of care consistent with his/her individual characteristics and needs.

Biographical work is an integral part of the support for the older people. Experience and feelings from the past very often play an important role in the present life of older

\footnotetext{
*Correspondence to: Mariya DIMOVA, Medical College of Trakia University, 9 Armeiska Str, Stara Zagora 6000, Bulgaria, E-mail:

mdimovameister@gmail.com, Phone: +359 899167091
}

people. In the process of gathering biographical information, there are important aspects of an older person's life history that should be captured. (1)

Especially, when it comes to people with dementia, who often retreat into the past, biographical data can help geriatric specialists access them, as the biographical work is an extremely important resource for their work, helping them strengthen the identity of the older people.

The objective of this study is to explore the attitudes and opinion of the "Geriatric care" students at the Medical College of Trakia University, Stara Zagora, to work with their personal biography in the training process.

\section{MATERIALS AND METHODS}

questionnaire survey, processing of questionnaire data and analysis 


\section{DISCUSSION AND RESULTS}

Since the 2014/2015 academic year, the first geriatric specialists in the country, majoring in "Geriatric care" have been receiving training in the Medical College at the Trakia University.

The most important competencies of the geriatric specialists are based on proper communication with older and elderly people in the process of looking after and caring for them, assuming that each care-dependent person should live according to his/her personal values, cultural and religious backgrounds and needs.

Their Qualification Characteristics specified that a geriatric specialist has to be able to "work with biography: through an individual interview or in discussion groups, in order to encourage older and elderly people to tell their life stories." (2)

Before getting into direct work with real older and elderly people and starting to implement the biography work, geriatric specialists have to acquire theoretical knowledge and gain practical experience during the practical exercises.

Initially, they pass through a biographical introspection, after presenting their personal biography, working in pairs and in groups, exploring their own life story.

A questionnaire survey of all "Geriatric care" students has been conducted, which aims a study to be carried out on their opinion on the work with their personal biography in the training process.

The questionnaire survey involved 12 women and 3 men with diverse age composition: 4 students aged 19 years; 2 students aged 20 years; 3 students aged 21 years, 1 of the students are respectively at the age of 23 years, 28 years, 33 years, 37 years, 38 years и 43 years. (Figure 1)

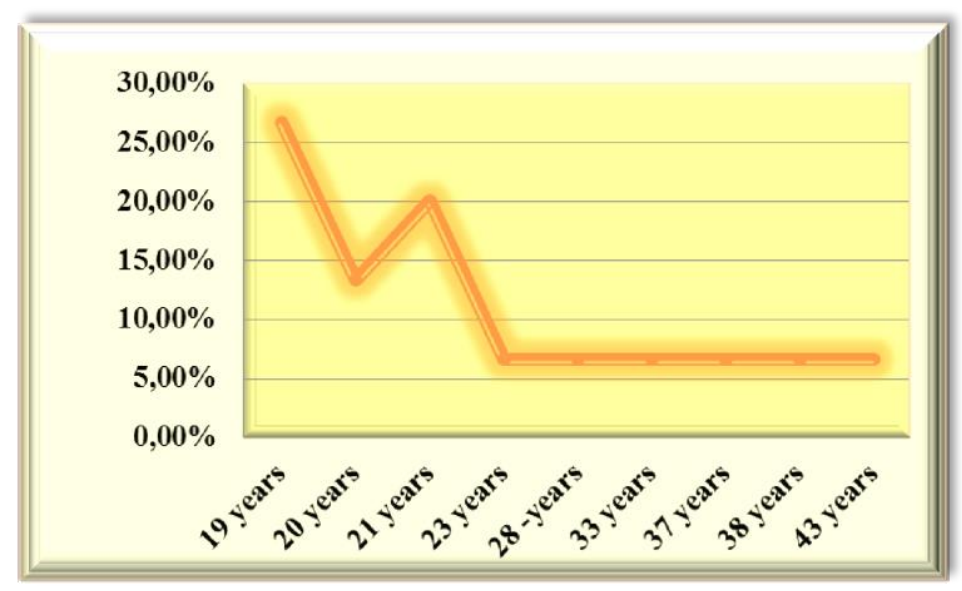

Figure 1. Age Distribution of students participating in the survey

In completing the questionnaires, students are allowed to choose more than one answer.

When asked in which role they felt better when working with personal biography, $26.67 \%$ of the students indicated that they felt more comfortable in the role of an interviewer, $40 \%$ of students felt better in the role of an interviewee, and $33.33 \%$ of the students answered that they felt good playing both roles. (Figure 2)

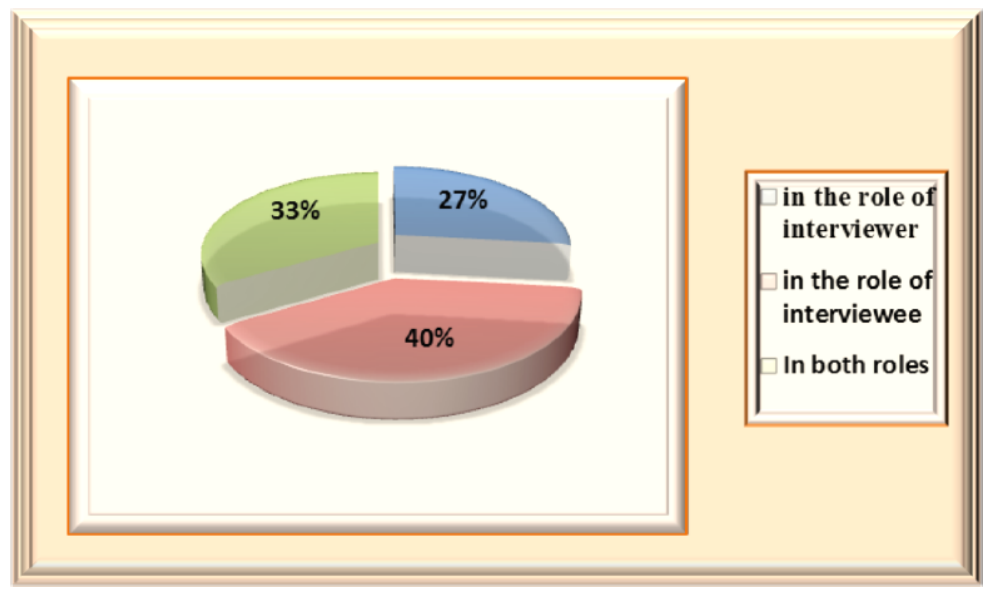

Figure 2. A role in which students felt better when working with personal biography 
When asked what they needed while working with their personal biography, in order to be able to reveal more important details of it, $33.33 \%$ of the students responded that they needed more time, $40 \%$ of them did not have enough confidence in the interviewer, $6.67 \%$ of the students responded that they needed more time and confidence in the interviewer, and $20 \%$ of students indicated that they did not need anything else, as they felt comfortable sharing. (Figure 3)

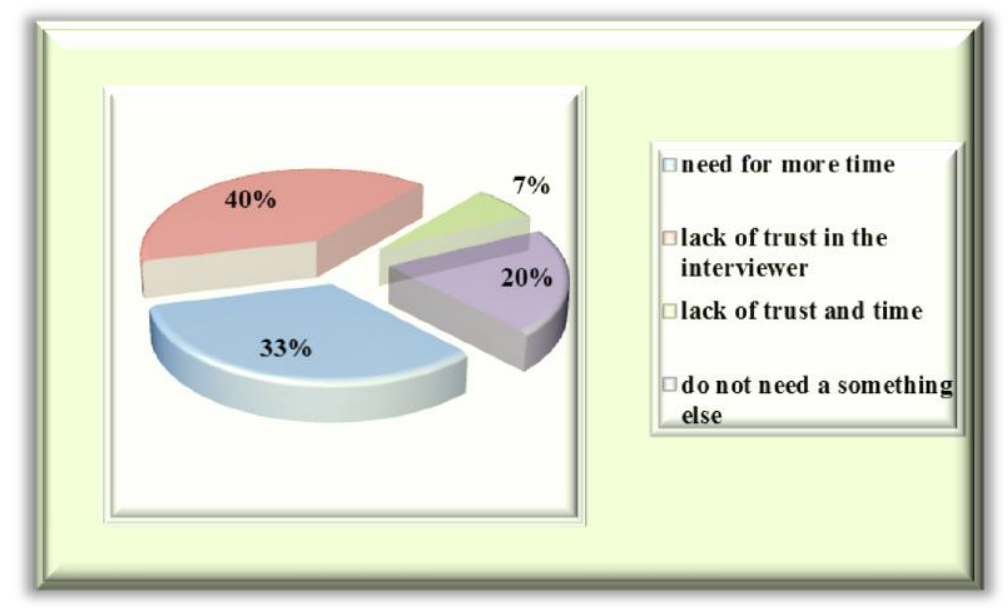

Figure 3. What else do the students need while working with their personal biography

When asked whether, when working with their personal biography for the first time, they had shared their personal traumatic experiences,
$46.67 \%$ of the students responded strongly negatively, while $53.33 \%$ indicated that they had partially done so. (Figure 4)

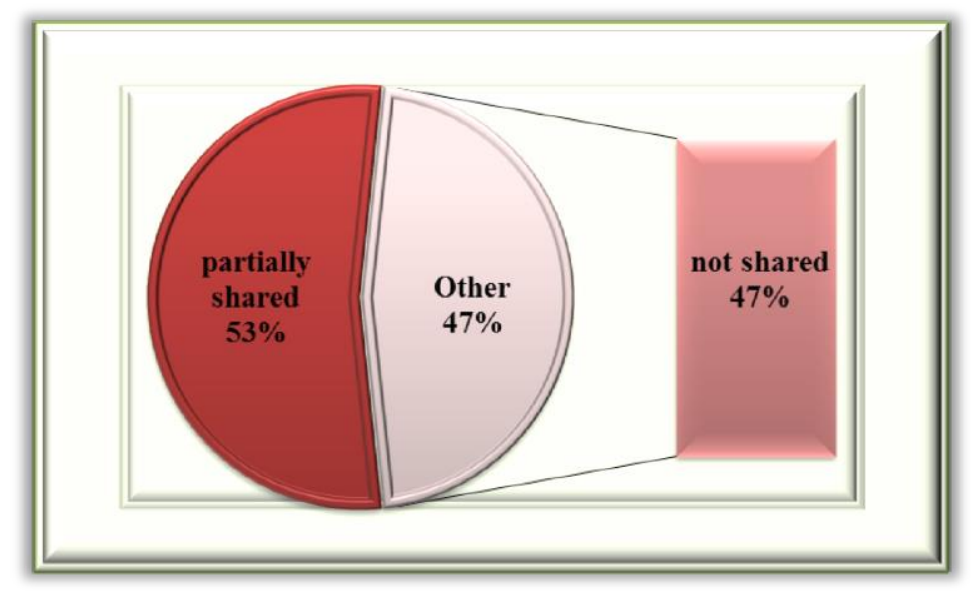

Figure 4. Degree of confidence in respect of sharing personal traumatic experiences

When asked whether they had experienced difficulties in completing the biographical sheet for the first time, $26.67 \%$ of the students responded affirmatively, $53.33 \%$ of the students responded negatively, and $20 \%$ had experienced partial difficulties. (Figure 5)

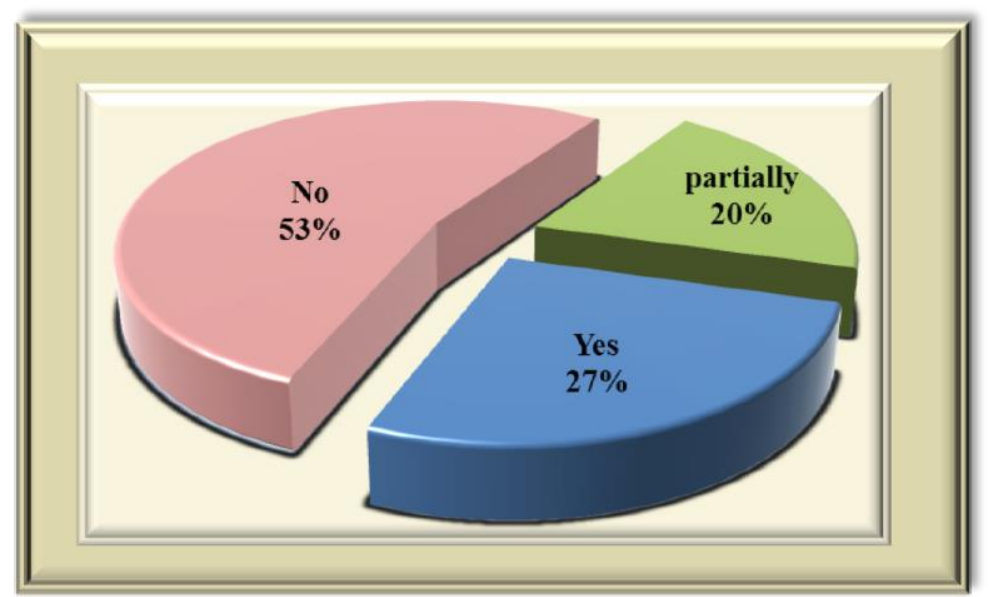

Figure 5. Difficulties in completing the biographical sheet for the first time 
DIMOVA M., et al.

As regards the reasons for the difficulties in completing the biographical sheet, $20 \%$ of the students indicated that it was something new to them and they needed time to understand each question, $6.67 \%$ of the students indicated the same reason, as they also added that they were afraid to ask personal questions and avoided offending the interviewee in any way, and $20 \%$ of the students had not encountered difficulties. (Figure 6)

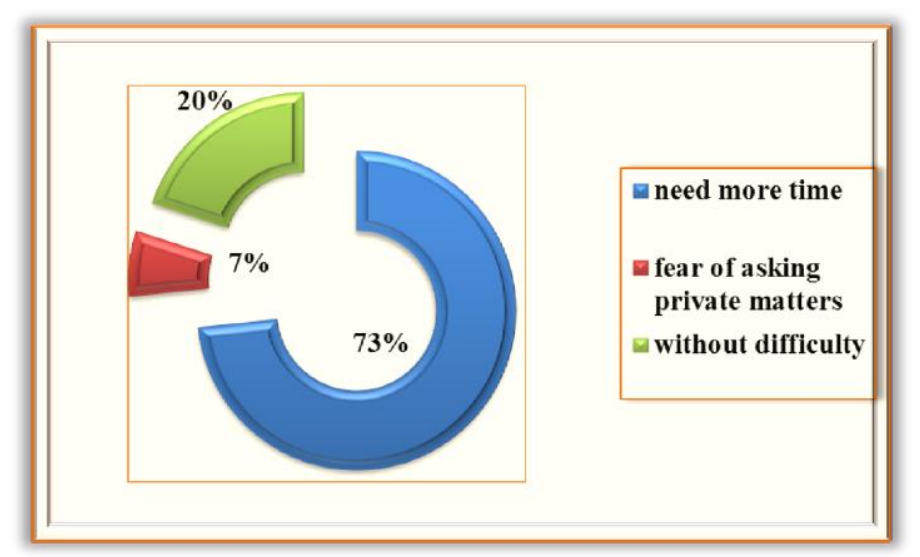

Figure 6. Type of difficulties when completing the biographical sheet for the first time

When asked what else they needed when working with personal biography, $33.33 \%$ of the students responded they needed more detailed theoretical training, 20\% of the students needed more hours of practical training, $6.67 \%$ of the students needed more theoretical and practical training, and $40 \%$ found the theoretical and practical training sufficient. (Figure 7)

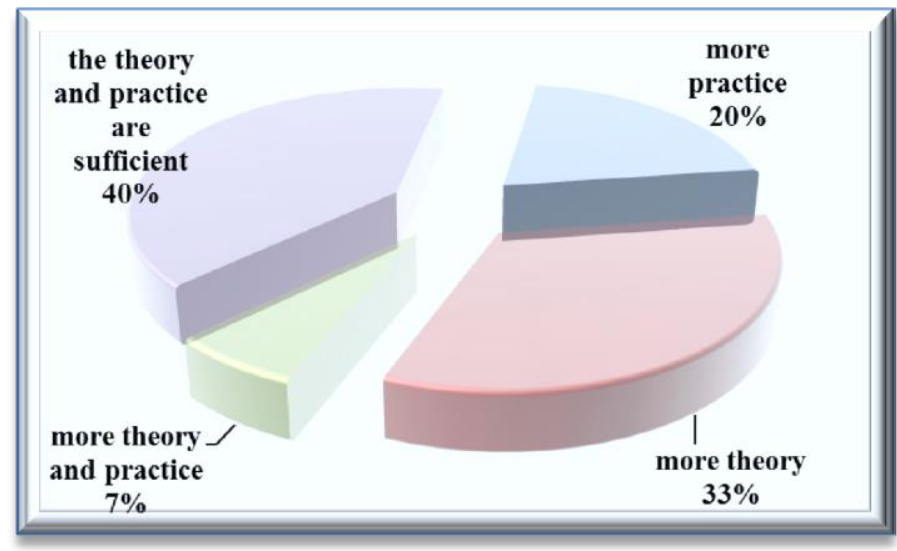

Figure 7. Students' opinion on the need for further training for work with personal biography

When asked how working with personal biography helped them, $20 \%$ of the students answered that they were able to understand themselves better, for $60 \%$ of the students this kind of work helped to know better the other students with whom they were working in a group for practical training, $13.33 \%$ of the students said they got to know themselves and other students in the group better, and $13.33 \%$ of the students believed that working with their personal biography did not helped them in any way. (Figure 8)

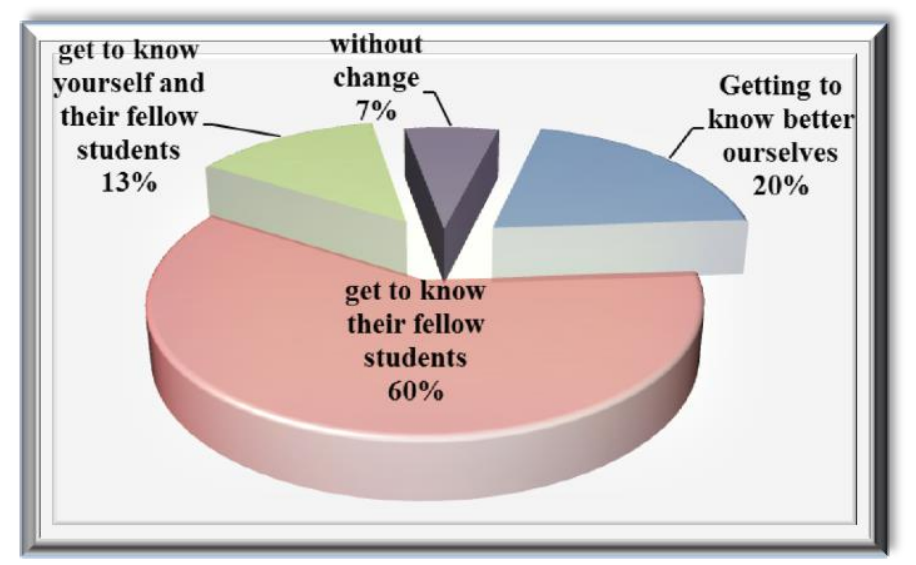

Figure 8. Students' opinion on the initial benefit from working with their personal biography

Trakia Journal of Sciences, Vol. 13, Suppl. 2, 2015 
In the part of the questionnaire, in which students are invited to express their summary opinion on the work with their personal biography, students indicated that it would be of great benefit to their future work as geriatric specialists, 3 students indicated that it helped them know their colleagues, 1 student was of the opinion that it helped him/her to better know his/her colleagues and that it would be of great benefit to his/her future work, 3 students were of the opinion that work with personal biography was an important part of their training, helped them better understand themselves and their colleagues, and would be of great benefit to their future work, and 1 student believed that kind of work would not be of benefit to him/her. (Figure 9)

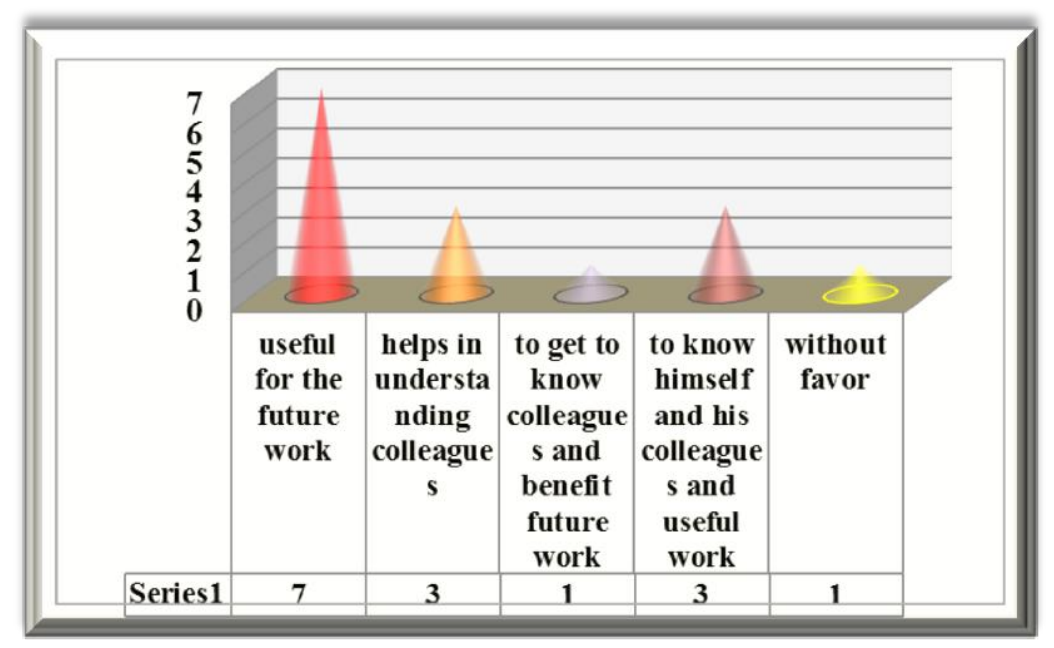

Figure 9. Summary opinion of the students on the benefits of the method for working with personal biography

In the part of the questionnaire intended for expressing recommendations in free text format, students' recommendations were mainly addressed at providing more practical work.

\section{CONCLUSIONS}

The analysis of the questionnaire survey results shows that students, in the beginning of their training, are afraid of revealing very personal and traumatic experiences and need more practical exercises and time for introspection and training in working with their personal biography and biographical sheet.

\section{REFERENCES}

1. K. Kostov, Hr. Milcheva, M. Dimova, "Home Care" Training Guide for geriatric specialists", Academic Publishing House of Trakia University, Stara Zagora, 2015, ISBN 978-954-338-116-6.

2. Qualification Characteristics of "Geriatric care" specialty at the Medical College of Trakia University, Stara Zagora 